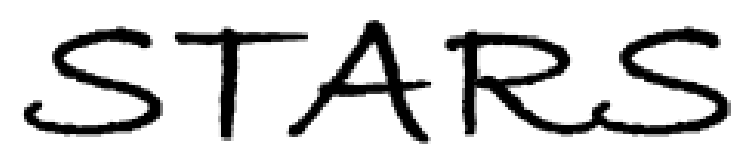

University of Central Florida

STARS

$9-1-2010$

\title{
Food Safety at Fairs and Festivals: Vendor Knowledge and Violations at a Regional Festival
}

Ji-Eun Lee

University of Central Florida, ji-eun.lee@ucf.edu

Barbara A. Almanza

Douglas C. Nelson

Part of the Hospitality Administration and Management Commons, and the Tourism and Travel Commons

Find similar works at: https://stars.library.ucf.edu/rosenscholar

University of Central Florida Libraries http://library.ucf.edu

This Paper is brought to you for free and open access by the Rosen College of Hospitality Management at STARS. It has been accepted for inclusion in Rosen Faculty Scholarship and Creative Works by an authorized administrator of STARS. For more information, please contact STARS@ucf.edu.

\section{Original Citation}

Lee, J., Almanza, B., Nelson, D., Cai, L. (2010). Food safety at fairs and festivals: Vendor knowledge and violations at a regional festival, Event Management, 14(3), 315-223

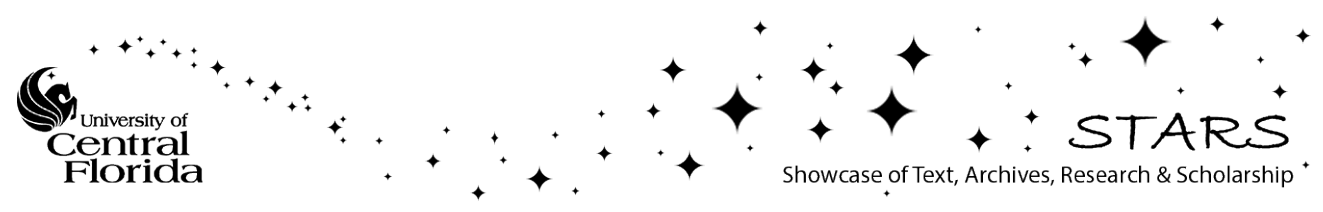




\title{
FOOD SAFETY AT FAIRS AND FESTIVALS: VENDOR KNOWLEDGE AND VIOLATIONS AT A REGIONAL FESTIVAL
}

\author{
JI-EUN LEE, BARBARA A. ALMANZA, and DOUGLAS C. NELSON
}

Department of Hospitality and Tourism Management, Purdue University, West Lafayette, IN, USA

\begin{abstract}
This 2-year study examined the food safety knowledge of food vendors at one of Indiana's largest festivals, and compared it with health inspection violations at this event. Ninety-four percent of nonprofit food vendors in 2006 and 100\% of nonprofit food vendors in 2008 participated. Descriptive statistics, correlation matrices, and general linear models (GLM) were employed. Results for average knowledge scores were that respondents were able to correctly answer 6.16 out of 10 questions (62\%) in 2006 and 10.2 out of 14 (73\%) in 2008. Results from the correlations and the GLM showed that vendors serving temperature control for safety (TCS) food had significantly higher knowledge scores in 2006. Vendors' ages $(p<0.05)$ and attendance at the educational workshop $(p<0.1)$ impacted the vendors' knowledge scores significantly in 2008 . Food safety knowledge and inspection violations were not found to be correlated. Several implications are suggested for training programs to improve vendors' food safety knowledge, and practices.
\end{abstract}

Key words: Food safety knowledge; Vendors; Fairs and festivals; Violations

\section{Introduction}

Millions of people attend thousands of fairs and festivals annually and these events greatly impact our communities. For instance, fairs and festivals bring economic benefits, generate revenue, increase employment opportunities, and promote organizations and business (Gursoy, Kim, \& Uysal, 2004; Thrane, 2002). In terms of social and cultural benefits, these events can enhance the community image, build community pride, and help preserve the local culture (Gursoy et al., 2004). In addition, these events offer recreation activities for family, attract visitors, and encourage better relationships between residents and visitors (Gursoy et al., 2004; Rao, 2001; Thrane, 2002). Food at fairs and festivals provides an opportunity to experience new cultures. A positive cultural experience through food might leave lasting impressions of the destination and motivate repeat visitation (Silkes, 2007).

However, there are also possible negative impacts. For instance, traffic congestion and the crime rate could increase and these events can put pressure on local services, such as police and fire protection, sanitation, and public transportation 
(Gursoy et al., 2004). In addition, outbreaks of food-borne illness at these events could have farreaching negative effects. Depending on the illness, visitors returning home could transport the microorganisms with them, increasing the spread of the disease. Media coverage of the event could damage the reputation of the event and local area, resulting in reduced tourism revenue (Fleming, Thorson, \& Zhang, 2006; Mitchell, 2006).

Previous studies (Boo, Ghiselli, \& Almanza, 2000; Mitchell, 2006) have suggested that attendees at fairs and festivals are very concerned about food safety. Their concerns may be well founded as several studies have documented outbreaks of food-borne illness at fairs and festivals (Cote et al., 1995; Lee et al., 1991; Millard et al., 1994; Morgan et al., 1994). Even though consumers do not always practice appropriate food safety behaviors at home, they expect the highest quality of food in eating places (Coleman, Griffith, \& Botterill, 2000). If an outbreak of food-borne illness should occur at fairs and festivals, it would very likely have a significant negative impact on the profitability of these events, which in turn would adversely affect the image of the community sponsors (Boo et al., 2000). Worsfold (2003) has suggested that food vendors at fairs and festivals need greater hygiene awareness and a better understanding of the requirements of the relevant sanitation regulations. The purpose of this study was to gain a better understanding of the food safety knowledge of food vendors at one of Indiana's largest festivals, the Feast of the Hunters' Moon, and determine common health inspection violations at this event.

\section{Literature Review}

Researchers have traced a number of foodborne illness outbreaks to fairs and festivals (Cote et al., 1995; Lee et al., 1991; Millard et al., 1994; Morgan et al., 1994). In addition, Boo et al. (2000) found that food served at fairs and festivals is perceived as significantly less safe than food served at cafeterias and other restaurants. Consumers' top three major concerns at these events were reported to be food poisoning/spoilage $(62.7 \%)$, dirt or dust contamination $(30.7 \%)$, and insect contamination $(25.3 \%)$. As part of the same study (Boo et al.,
2000), participants were asked about vendor practices that they felt most compromised food safety. Their three major concerns were that vendors do not cook foods thoroughly $(23.7 \%)$, that vendors do not properly clean equipment and utensils $(21.7 \%)$, and unhygienic practices by food handlers (16.4\%).

With food safety being such an important issue, it is not surprising that organizers share consumers' concerns. Organizers at fairs and festivals have stated that inexperienced traders and exhibitors attending these events have made food safety/ hygiene mistakes or had insufficient hygiene knowledge (Worsfold, 2003), such as unsatisfactory hand washing and temperature control, lack of food handling and crisis management strategies (Worsfold, 2003). Other concerns identified by the organizers included opportunities for cross contamination, inadequate storage arrangements, lack of fire extinguishing equipment, and problems with safety of generators and cooking fuel (Worsfold, 2003).

Possible reasons for poor food safety practices have been researched. Campbell and Beaty (1971) and Griffin and Neal (2000) argued that the three determinants of individual performance are knowledge, skill, and motivation. Griffin and Neal (2000) developed a framework to link safety climate to safety performance, knowledge, and motivation. They found that safety knowledge only partially mediated the link between safety climate and safety performance dimensions. In addition, the path from safety knowledge to safety participation (one dimension of safety performance) was also not statistically significant. These results were consistent with the previous research conducted by Binkley (2005), finding that food safety knowledge did not impact food safety performance significantly in restaurants. These results imply that there was a gap between what employees know and what they do at workplaces.

One way the State of Indiana has tried to improve food safety practices have been to require managers to be certificated in safe food handling through an accredited organization. Even though fairs and festivals in Indiana are classified as temporary food service operations and not permanent foodservice operations, they are normally required to meet the requirement of at least one certified 
food handler on staff. One exception to this rule, however, is that nonprofit organizations at fairs and festivals need not have a certified manager, or even undergo a health inspection (Indiana State Department of Health, 2005). Unfortunately, many Indiana fairs and festivals include numerous nonprofit organization food vendors, which are manned by volunteers. Those volunteers are not likely to have had food safety training and little or no commercial food service experience. These workers may use improper handling procedures due to inexperience with large volumes of food or use of home food handling techniques (Manning \& Snider, 1993). This in turn may increase the public's food safety risk when dining at fairs and festivals.

As an alternative to health department inspections, "guidance sessions" that offer information as to what health officials may look for in inspections may be conducted with nonprofit vendors during fairs and festivals events if event sponsors request them. These sessions are in fact conducted at the request of the Sponsors of the Feast of the Hunters' Moon to educate vendors about potential violations in their operation. They are used as an alternative to inspections because of the nonprofit exemption, which does not permit health inspections of nonprofit operations. Because of the use of this alternative method of food guidance rather than inspection, the purpose of this study was to gain a better understanding of the food safety knowledge of food vendors at one of Indiana's largest festivals, the Feast of the Hunters' Moon, and determine common health inspection "violations" at this event. The Tippecanoe County Health Department will use this information to develop an educational workshop for vendors of future events.

\section{Methodology}

This study was conducted with the support of the Tippecanoe County Health Department. In order to assess the food safety knowledge of vendors at the Feast of the Hunters' Moon, a questionnaire was developed in the fall of 2006 using information from the Tippecanoe County Health Department temporary food service guidelines (2006). In 2008 the questionnaire was modified slightly based on the Health Department's new checklists (Tippecanoe County Health Department, 2008). The 2006 questionnaire included 10 knowledge questions and focused on the most frequently cited risk factors in food-borne illness outbreaks: temperature control, preparation of food, personal hygiene, and reheating (County of Los Angeles Public Health, 2006). The type of questions was a Yes/No single answer format. The correct answers were provided by the Tippecanoe County Health Department temporary food service guidelines. The questionnaire was reviewed by the local health department and faculty at Purdue University. In 2008, four additional knowledge questions based on the most frequent violations from the county's inspection results for 2006 were added. These additional questions covered food protection from potential contamination, dishwashing facilities (concentrations of chemical sanitizer and usage of proper test kit), and hygiene/personal cleanliness (proper hair restraints).

In addition, the questionnaire in 2008 assessed the impact of an educational workshop provided by the Department of Health. In 2008, vendor identification numbers were recorded on surveys and matched with attendance at the Department of Health educational workshop. Because of this procedure, data were only analyzed in aggregate so as to not identify individual respondents by identification number thereby assuring confidentiality of the respondents.

Questionnaires were distributed and collected face-to-face by one of the researchers during the first day of the event (October 7) in 2006. In 2008, the questionnaires were distributed by the Tippecanoe County Health Department to vendors during the first day of the event (September 27) upon completion of the Health Department's "guidance sessions." Respondents in both 2006 and 2008 were informed that their participation was voluntary and that their results would be kept anonymous. In 2006, the surveys were returned to the student distributing them upon completion by participants. The questionnaires distributed in 2008 were collected by a student on September 28. This procedure allowed the respondents to remain anonymous (to the health department) and not feel pressured by the health department to answer the questionnaire. 
Statistical analyses were conducted using SAS program version 9.1 and Microsoft office Excel 2003. In order to evaluate the food safety knowledge and determine the common violations at this event, descriptive statistics, including frequency distribution, mean, and SD were used. Correlation matrices and general linear models (GLM) were employed to examine the significant impact of independent variables on the dependent variable.

To use a GLM, assumptions must be made: independence and normal distribution of dependent variable $(Y)$. The dependent variable in this study was food safety knowledge at the Feast of the Hunters' Moon. Vendors' knowledge was assessed through a series of question on the questionnaire. Surveys were conducted without prenotice by health inspectors or researchers. The knowledge scores were assumed to be independent observations among the vendors' booths at the Feast because they had no prenotice and each participant completed the survey independently. The results from Levene's test of equality of error variances showed that the error variance of the dependent variable was equal across groups. Therefore, the knowledge scores met the assumption of homogeneity. In order to check whether data had a normal distribution, qqplot in Proc Univariate and plot in the Proc gplot procedures were conducted. The food safety knowledge questions were developed from basic food safety information of which all food handlers should be aware. As expected, the distributions were slightly left-skewed $(-0.44)$ and a kurtosis of -1.18 , which is within a standard normal distribution. Independent variables were: attendance at an educational workshop given by the Health Department; food certification; work experience; education; gender; and age. The independent variables, the attendance of training (i.e., educational workshop) and food handler certification, used a binary indicator (attended the training program $=1$, did not attend the training program $=$ 0 ; certified in safe food handling $=1$, not certified $=0)$.

\section{Results and Discussion}

\section{The 2006 Study}

In 2006, 32 out of 34 vendors (94\%) participated. The majority $(78 \%)$ were nonprofit organi-
Table 1

Demographic Profile of the Respondents

\begin{tabular}{lcc}
\hline & $\begin{array}{c}2006 \\
(n=31)^{\mathrm{a}}\end{array}$ & $\begin{array}{c}2008 \\
(n=28)^{\mathrm{b}}\end{array}$ \\
Characteristics & $\begin{array}{c}\text { [Number }(\%)] \\
{[\text { Number }(\%)]}\end{array}$ \\
\hline $\begin{array}{l}\text { Gender } \\
\text { Female }\end{array}$ & $18(58 \%)$ & $17(61 \%)$ \\
Male & $13(42 \%)$ & $11(39 \%)$ \\
Age & $0(0 \%)$ & $2(8 \%)$ \\
$26-30$ & $6(20 \%)$ & $4(17 \%)$ \\
$31-40$ & $11(37 \%)$ & $7(29 \%)$ \\
$41-50$ & $6(20 \%)$ & $7(29 \%)$ \\
$51-60$ & $7(23 \%)$ & $4(17 \%)$ \\
61 and above & & \\
Education level & $0(0 \%)$ & $1(4 \%)$ \\
Some high school, but & $5(16 \%)$ & $6(23 \%)$ \\
$\quad$ no diploma & $2(6 \%)$ & $0(0 \%)$ \\
High school ciploma & & \\
Two years of college & $3(10 \%)$ & $3(12 \%)$ \\
Some culinary/technical & & \\
$\quad$ school/college & & \\
Graduated from & & \\
$\quad$ culinary/technical & $1(3 \%)$ & $2(8 \%)$ \\
$\quad$ school & $3(10 \%)$ & $3(12 \%)$ \\
Associate degree & $6(19 \%)$ & $3(31 \%)$ \\
Bachelor degree & $3(12 \%)$ \\
Graduate degree &
\end{tabular}

${ }^{\mathrm{a}} 78 \%$ of respondents in 2006 were nonprofit organizations. ${ }^{\mathrm{b}} 100 \%$ of respondents in 2008 were nonprofit organizations.

zations, and $28 \%$ of respondents were certified by ServSafe, Experior, or other certification programs, even though they were exempt from the certification requirement. Fifty-eight percent were female and the mean age was 50 with a range of 33-71 years. Tables 1 and 2 show the profile of the respondents. The majority (84\%) of respondents worked as a manager or supervisor.

Table 2

Foodservice Work Experience of the Respondents

\begin{tabular}{lcc}
\hline $\begin{array}{l}\text { Years of Work } \\
\text { Experience }\end{array}$ & $\begin{array}{c}2006 \\
(n=30) \\
\text { [Number }(\%)]\end{array}$ & $\begin{array}{c}2008 \\
(n=27) \\
\text { [Number }(\%)]\end{array}$ \\
\hline 0 (none) & $11(37 \%)$ & $14(52 \%)$ \\
$1-5$ & $10(33 \%)$ & $6(22 \%)$ \\
$6-10$ & $2(7 \%)$ & $2(7 \%)$ \\
$11-15$ & $1(3 \%)$ & $2(7 \%)$ \\
$16-20$ & $1(3 \%)$ & $1(4 \%)$ \\
$21-25$ & $1(3 \%)$ & $2(7 \%)$ \\
26 or more & $4(13 \%)$ & $0(0 \%)$ \\
\hline
\end{tabular}


Fifty-six percent of the vendors at the Feast of the Hunters' Moon in 2006 sold foods that need time and temperature control for safety (TCS), such as meats, fish, buffalo chowders/stews, omelets, potatoes, and noodles (Table 3), but only $22 \%$ knew the temperature danger zone for TCS foods. In addition, only $22 \%$ of the respondents correctly answered the question regarding reheating for TCS foods. Also surprising was the fact that only $72 \%$ correctly answered the hand washing question ("does a tub of soapy water provide an acceptable way to wash hands?") and $91 \%$ correctly answered the question regarding the prohibition of bare hand contact with food (Table 4). As Table 4 shows, $50 \%$ or fewer vendors knew about the proper temperature control for TCS foods, such as the TCS danger zone, the pork cooking endpoint, the ground beef cooking endpoint, and adequate reheating temperatures. Temperature control is one of the most frequently cited risk factors to food-borne illness outbreaks (County of Los Angeles Public Health, 2006).

The average knowledge score in 2006 was 6.16 out of $10(62 \%)$ with a standard deviation of 1.7 (Table 5). Correlations were found to be significant $(p<0.1)$ among specific knowledge questions (required cooking temperatures for ground beef and reheating, prohibition of home prepared food, acceptable hand washing practices, and TCS danger zone temperatures) and the knowledge

Table 3

Menu Sold at the Feast

\begin{tabular}{lcc}
\hline Menu & $\begin{array}{c}2006 \\
(n=32)\end{array}$ & $\begin{array}{c}2008 \\
(n=28)\end{array}$ \\
\hline Meats $^{\mathrm{a}}$ & 10 & 11 \\
Chowders $^{\mathrm{a}}$ & 5 & 5 \\
Buffalo stew $^{\mathrm{a}}$ & 1 & 0 \\
Fish $^{\mathrm{a}}$ & 1 & 1 \\
Potatoes $^{\mathrm{a}}$ & 1 & 3 \\
Omelets $^{\mathrm{a}}$ & 1 & 0 \\
Noodles $^{\mathrm{a}}$ & 1 & 1 \\
Bread & 5 & 7 \\
Beverage & 15 & 13 \\
Vegetables & 1 & 1 \\
Candy & 6 & 3 \\
Desserts & 0 & 1 \\
\hline
\end{tabular}

Respondents checked all that apply.

${ }^{a}$ Food that need time and temperature control for safety (TCS).
Table 4

Results of the Knowledge Questions

\begin{tabular}{|c|c|c|}
\hline & $\begin{array}{c}2006 \\
(n=32) \\
{[\text { Number }(\%)]}\end{array}$ & $\begin{array}{c}2008 \\
(n=28) \\
{[\text { Number }(\%)]}\end{array}$ \\
\hline TCS danger zone & $7(22)^{\mathrm{a}}$ & $4(14)^{\mathrm{a}}$ \\
\hline Poultry cooking endpoint & $19(59)$ & $20(71)$ \\
\hline Pork cooking endpoint & $13(41)^{\mathrm{a}}$ & $12(43)^{\mathrm{a}}$ \\
\hline $\begin{array}{l}\text { Ground beef cooking end- } \\
\text { point }\end{array}$ & $16(50)^{\mathrm{a}}$ & $16(57)$ \\
\hline $\begin{array}{l}\text { Proper storage of equip- } \\
\text { ment }\end{array}$ & $31(97)$ & $25(89)$ \\
\hline $\begin{array}{l}\text { Reheating temperature re- } \\
\text { quirement }\end{array}$ & $7(22)^{\mathrm{a}}$ & $8(29)^{a}$ \\
\hline $\begin{array}{l}\text { Prohibition of home pre- } \\
\text { pared food }\end{array}$ & $22(69)$ & $26(93)$ \\
\hline $\begin{array}{l}\text { Prohibition of smoking/ } \\
\text { eating }\end{array}$ & $30(94)$ & $25(89)$ \\
\hline Proper hand washing & $23(72)$ & $22(79)$ \\
\hline $\begin{array}{l}\text { Prohibition of bare hand } \\
\text { contact }\end{array}$ & $29(91)$ & $25(89)$ \\
\hline Proper food storage & & $24(86)$ \\
\hline $\begin{array}{l}\text { Availability of sanitizer } \\
\text { test kit }\end{array}$ & & $27(96)$ \\
\hline Use of hair restraints & & $24(86)$ \\
\hline $\begin{array}{l}\text { Calibration of thermome- } \\
\text { ters }\end{array}$ & & $25(89)$ \\
\hline
\end{tabular}

Values are umber and percentage of respondents who answered each question correctly.

${ }^{\mathrm{a} K n o w l e d g e ~ q u e s t i o n s ~ w i t h ~ c o r r e c t ~ s c o r e s ~ o f ~} 50 \%$ or less.

Table 5

Composite Knowledge Score

\begin{tabular}{|c|c|c|}
\hline Score & $\begin{array}{c}2006 \\
(n=32)^{\mathrm{a}} \\
{[\text { Number }(\%)]}\end{array}$ & $\begin{array}{c}2008 \\
(n=28)^{\mathrm{b}} \\
{[\operatorname{Number}(\%)]}\end{array}$ \\
\hline 3 & $3(9 \%)$ & \\
\hline 4 & $3(9 \%)$ & \\
\hline 5 & $4(13 \%)$ & \\
\hline 6 & $6(19 \%)$ & $1 \quad(4 \%)$ \\
\hline 7 & $11(34 \%)$ & $2(7 \%)$ \\
\hline 8 & $2(6 \%)$ & $6(21 \%)$ \\
\hline 9 & $3(9 \%)$ & $1(4 \%)$ \\
\hline 10 & & $4(14 \%)$ \\
\hline 11 & & $3(11 \%)$ \\
\hline 12 & & $10(36 \%)$ \\
\hline 13 & & $1(4 \%)$ \\
\hline
\end{tabular}

Composite knowledge score refers to the number of correct answers by each respondent. Number and percentage represent the frequency of the composite knowledge score.

${ }^{a}$ Average: 6.2 out of a maximum score of $10(62 \%)$ with a SD of 1.7 based on the number of correctly answered questions.

${ }^{b}$ Average: 10.2 out of a maximum score of $14(73 \%)$ with a SD of 1.7 based on the number of correctly answered questions. 
score. Average knowledge score for males (based on the number of correctly answered questions) was 6.76 out of 10 and 5.66 out of 10 for females. Serving TCS foods was significantly correlated with knowledge $(p<0.05)$. The results from the GLM procedure also indicated there was a significant mean difference between vendors serving TCS foods and those not serving TCS $(p<0.05)$. In other words, vendors serving TCS foods tended to have higher knowledge scores. About $63 \%$ of the vendors at the Feast had attended a previous educational workshop for this Feast provided by the Department of Health. Attendance at this workshop, certification, gender, age, education, and work experience, however, were not significantly correlated with knowledge score.

\section{The 2008 Study}

In $2008,100 \%$ of nonprofit organizations participated. Sixty-one percent of the respondents were female in 2008 (compared to 58\% in 2006) and the mean age was 49 years with a range of 26-73 years (Table 1). Table 2 shows that $52 \%$ of the vendors had no work experience in food service establishments in 2008, up from 37\% in 2006. About $64 \%$ of the vendors at the Feast of the Hunters' Moon in 2008 sold TCS foods; however, only $14 \%$ knew the temperature danger zone for TCS foods. Also, only $29 \%$ of the respondents correctly answered the question regarding reheating for TCS foods, $79 \%$ correctly answered the hand washing question, and $89 \%$ respondents correctly answered the question on bare hand contact (Table 4). As Table 4 shows, $43 \%$ or fewer vendors knew about the proper temperature control for TCS foods, such as the TCS danger zone, the pork cooking endpoint, and adequate reheating temperatures.

The average knowledge score in 2008 was 10.2 out of $14(73 \%)$ with a SD of 1.7 (Table 5). Correlations were found to be significant $(p<0.05)$ among specific knowledge questions (the required cooking temperatures for poultry, pork, and ground beef and adequate reheating temperatures, prohibition of home prepared food, acceptable hand washing practices, proper food storage, and availability of a sanitizer test kit) and the knowledge score. Average knowledge score for males was 10.81 out of 14 questions and for females was 10.07 out of 14 . About $59 \%$ of the vendors at the Feast attended the educational workshop for this Feast provided by the Department of Health and attendance at this workshop was significantly correlated with knowledge score $(p<0.1)$, but not gender, education, certification, and work experience. The results from the GLM procedure indicated there was also a significant mean difference among vendor's age $(p<0.05)$ and attendance at the workshop $(p<0.1)$.

\section{Most Common Violations and the Relationship}

Between Food Safety Knowledge and the Number of "Violations" Found at the Feast

In 2006, the Health Department found 12 critical "violations" and nine noncritical "violations" at the Feast. In 2008, the Health Department found 11 critical "violations" and nine noncritical "violations." Critical and noncritical violations in 2006 and 2008 are shown in Table 6. The most common critical violation was incorrect sanitizer use. The most common noncritical violation was improper food protection during display and storage. Results in 2008 showed that food safety knowledge scores were not significantly related to the number of "violations" found. In other words, higher food safety knowledge scores did not result in fewer "violations" being found by the health inspectors, implying that there is a gap between what food vendors know and what they do. This is consistent

\section{Table 6}

Violations Found at the Feast

\begin{tabular}{lcc}
\hline & $\begin{array}{c}2006 \\
(n=32)\end{array}$ & $\begin{array}{c}2008 \\
(n=28)\end{array}$ \\
\hline Description & & \\
Critical violations & 7 & 6 \\
$\quad$ Incorrect sanitizer use & 4 & 3 \\
$\quad$ Improper food temperatures & 1 & 2 \\
$\quad$ Bare hand cvontact & 12 & 11 \\
$\quad$ Total & & \\
Noncritical violations & 4 & 5 \\
$\quad$ Improper food protection during & & \\
$\quad$ display/storage & 2 & 2 \\
$\quad$ No hair restraint and use of nail & 2 & 2 \\
$\quad$ rolish & 1 & 0 \\
Improper equipment storage & 9 & 9 \\
$\quad$ No food labels & & \\
Total & & \\
\hline
\end{tabular}


with previous studies (Brinkley, 2005; Griffin \& Neal, 2000).

Knowledge of some vendors did appear to be a concern. Although not all vendors sold TCS food, at a minimum those that did serve TCS food should have been able to answer knowledge questions about TCS food correctly. In other words, answers to such questions in 2006, for example, should at least have been answered correctly by all respondents that served TCS foods (58\%), but less than one fourth (and less than half of those serving TCS foods) answered this question correctly. Considering that the failing inspection score for food establishments in the State of Indiana under the traditional system was 75 points out of 100 , all respondents should have been able to answer $75 \%$ of the questions correctly regarding food handling and hand washing whether they served TCS foods or not. The average knowledge score of 6.2 points out of 10 points (62\%) in 2006 and the average knowledge score of 10.2 points out of 14 points (73\%) in 2008 appear relatively low.

It is important to recognize that even though people may have high knowledge scores, they still may not handle foods safely. Even further, if they do not know what correct food safety practices are, they are not likely to practice appropriate behaviors. Results from this study suggest that the exemption of nonprofit organizations in food safety regulations may potentially be a problem for food safety at these events. In fact, the Department of Health found 12 critical violations and nine noncritical violations at the Feast in 2006 among 32 food venders and 11 critical violations and nine noncritical violations at the Feast in 2008 among 28 venders respectively (Table 6). More importantly, the same types of violations were found at the Feast in both 2006 and 2008. Especially, the risk associated with the same types of critical violations suggests the need to pay closer attention to these violations and might require further actions to reduce their occurrence. Examples of critical violations at these Feasts included: sanitizer registered too strong (over $200 \mathrm{ppm}$ ), cooked chicken and sausage registered below proper temperature, and food handler did not wash his hands after taking a drink and wiping his nose with his hand.

\section{Conclusion}

The objectives of this study were to examine the food safety knowledge of vendors of foods at one of Indiana's largest festivals, the Feast of the Hunters' Moon, and to determine common health inspection violations at this event. Descriptive statistics, including frequency distribution, mean and $\mathrm{SD}$, correlation matrices, and GLM were employed. The average knowledge scores in this study were 6.16 out of $10(62 \%)$ in 2006 and 10.2 out of 14 (73\%) in 2008 (Table 5). Results from the correlations and the GLM showed that vendors serving TCS foods tended to have significantly higher knowledge scores in 2006 (6.7 points for venders serving TCS foods; 5.3 for not serving TCS foods). Vendor's age $(p<0.05)$ and attendance at the educational workshop $(p<0.1)$ impacted the vendors' knowledge scores significantly in 2008. In addition, based on the results of the study, food safety knowledge was not significantly related to the number of violations found by the Department of Health. Even though vendors know how to handle food safely at these events, they did not practice appropriate behaviors. Some vendors did not know what and how to handle food safely and others did not have work experience in the foodservice area at all (37\% of respondents in 2006 and 52\% in 2008).

Given the vast number of attendees at festivals and events of this kind, there is great potential for problems if food products are not handled in a sanitary manner. For example, typical attendance at the Feast of the Hunters' Moon is approximately 40,000 people every year (Christos, 2006). If each attendee eats two or three times over the course of their visit, eating occasions could exceed 100,000 . The potential for food-borne illness is therefore very serious if food safety regulations were not followed and an outbreak should occur. In addition, the negative impact would destroy the positive image and socioeconomic benefits (valued at net revenue of approximately $\$ 200,000$ according to Slyder, 2008) of this event. Therefore, food venders at fairs and festivals need appropriate food safety knowledge, education (such as the educational workshop or as represented by food safety certification), practices, and inspec- 
tions to reduce the potential for food borne illness outbreaks at fairs and festivals.

Based on the results of this study, several suggestions could be made for effective training programs to improve vendors' food safety knowledge and practices. Specific temperature and thermometer guidelines should be elaborated upon because fewer respondents answered these questions correctly and their knowledge scores were highly correlated with these questions. In addition, training sessions should not be lecture based, but should include more hands-on training regarding appropriate food handling, the use of sanitizers, the bare hand contact rule, and hand washing to reinforce the application of these areas because violations still occurred in spite of relatively high knowledge scores. Training may improve food safety knowledge, but not always actual food safety practices, unless its application is clearly understood. Vendor attendance at the educational workshop appeared to increase their knowledge scores and was helpful because of the limited food service work experience of vendors (e.g., in $200852 \%$ of the respondents had no food service work experience). Finally, the Health Department educational workshop is offered in the spring for this event, which is held in the fall. If the Health Department were to provide the educational workshop nearer the event (late summer, for example) the effect of training may also be increased.

One limitation of this study is that one festival with a small sample size (32 in 2006 and 28 in 2008) was examined. Because of the limited number, it was not possible to sufficiently quantify the risks related to the food at this Feast; however, it is clear that food vendors at this Feast need to know more food safety knowledge and follow appropriate food safety practices. Further research is recommended to address the safe handling of foods at other fairs and festivals in additional jurisdictions and the issues of training, certification, and inspections at these events in order to reduce the gap between food vendors' knowledge about food handling and their behaviors at these events. The practice of exempting nonprofit vendors should also be reviewed. Finally, an instrument to measure socioeconomic impact of food safety at fairs and festivals on local communities should be developed.

\section{References}

Binkley, M. M. (2005). The impact of foodservice manager credentialing on food safety knowledge and health inspection scores. Unpublished doctoral dissertation, Purdue University, West Lafayette.

Boo, H. C, Ghiselli, R., \& Almanza B. A. (2000). Consumer perceptions and concerns about the healthfulness and safety of food served at fairs and festivals. Event Management, 6, 85-92.

Campbell, J. P., \& Beaty, E. E. (1971, September). Organizational climate: Its measurement and relationship to work group performance. Paper presented at the annual meeting of the American Psychological Association, Washington, DC.

Christos, J. (2006, October 6). 'Amazing' weather helps Feast. Journal \& Courier.

Coleman, P., Griffith, C., \& Botterill, D. (2000). Welsh caterers: An exploratory study of attitudes towards safe food handling in the hospitality industry. International Journal of Hospitality Management, 19(2), 145-157.

Cote, T. R., Convery, H., Robinson, D., Ries, A., Barrett, T., Frank, L., Furlong, W., Horan, J., \& Dwyer, D. (1995). Typhoid fever in the park: Epidemiology of an outbreak at a cultural interface. Journal of Community Health, 29(6), 451-458.

County of Los Angeles Public Health. (2006). Centers for disease control risk factors. Retrieved September 10, 2006, from https://lapublichealth.org/eh/rfig/rfigfiles/cdc risk.htm

Fleming, K., Thorson, E., \& Zhang, Y, (2006). Going beyond exposure to local news media: An informationprocessing examination of public perceptions of food safety. Journal of Health Communication, 11, 789-806.

Griffin, M. A., \& Neal, A. (2000). Perceptions of safety at work: A framework for linking safety climate to safety performance, knowledge, and motivation. Journal of Occupational Health Psychology, 5(3), 347-358.

Gursoy, D., Kim, K., \& Uysal, M. (2004). Perceived impacts of festivals and special events by organizers: An extension and validation. Tourism Management, 25(2), 171-181.

Indiana State Department of Health. (2005). Food handler certification now exempts non-profits. FoodBytes, 6(2), $1-6$.

Lee, A. L., Ostroff, S. M., McGee, H. B., Johnson, D. R., Gownes, F. P., Cameron, D. N., Bean, N. H., \& Griffin, P. M. (1991). An outbreak of shigellosis at an outdoor music festival. American Journal of Epidemiology, 133(6), 608-615.

Manning, C. K., \& Snider, O. S. (1993). Temporary public eating places: Food safety knowledge, attitudes and practices. Journal of Environmental Health, 56(1), 24-28.

Millard, P. S., Gensheimer, K. F., Addiss, D. G., Sosin, D. M., Beckett, G. A., Jankoski, A. H., \& Hudson, A. (1994). An outbreak of cryptosporidiosis from freshpressed apple cider. Journal of the American Medical Association, 272(20), 1592-1596. 
Mitchell, J. T. (2006). Conflicting threat perceptions at a rural agricultural fair. Tourism Management, 27, 12981307.

Morgan, D., Gunneberg, C., Cunnell, D., Healing, T. D., Lamerton, S., Soltanpoor, N., Lewis, D. A., \& White, D. G. (1994). An outbreak of campylobacter infection associated with the consumption of unpasteurized milk at a large festival in England. European Journal of Epidemiology, 10(5), 581-585.

Rao, V. (2001). Celebrations as social investments: Festival expenditures, unit price variation and social status in rural India. The Journal of Development Studies, 38(1), 71-97.

Silkes, C. A. K. (2007). Food and food related festivals in rural destination branding, Unpublished thesis, Purdue University, West Lafayette, Indiana.

Slyder, C. (2008). Financing the feast: Even with risky in- come, organizers believe in event. Retrieved September 28, 2008, from http://boilerstation.jconline.com/apps/pbcs. dll/article?AID=/20080928/NEWS/809280343/0/NEWS $\underline{0501}$

Thrane, C. (2002). Jazz festival visitors and their expenditures: Linking spending patterns to musical interest. Journal of Travel Research, 40(3), 281-286.

Tippecanoe County Health Department. (2006). Tippecanoe County Health Department temporary food service guidelines. Lafayette, IN: Author.

Tippecanoe County Health Department. (2008). Tippecanoe County Health Department temporary food establishment checklist. Lafayette, IN: Author.

US Public Health Service, Food and Drug Administration. (2005). Food code. Washington, DC: Author.

Worsfold, D. (2003). Food safety at shows and fairs. Nutrition \& Food Science, 33(4), 159-164. 